\title{
Perspectives of Portuguese People with Physical Disabilities Regarding Their Sexual Health: A Focus Group Study
}

\author{
Raquel Pereira ${ }^{1}$ (D) $\cdot$ Pedro M. Teixeira ${ }^{2} \cdot$ Pedro J. Nobre $^{1}$
}

(c) Springer Science+Business Media, LLC, part of Springer Nature 2018

\begin{abstract}
The World Health Organization has considered sexual health as a major dimension of global health and a sexual right. However, the sexual health of people with physical disabilities is still poorly addressed by health and social care professionals, and it is very stigmatized by society. This study aimed to assess the perspectives of Portuguese people living with physical disabilities regarding issues affecting their sexual health. Nine women and 17 men with different physical disabilities participated in the study. Participants were recruited from a professional rehabilitation facility located in the North of Portugal and were assigned to four groups in one-hour sessions. Three main categories emerged from the content analysis: (1) meanings and beliefs regarding sexuality; (2) experiences of sexuality; (3) necessary changes. Despite the positive social changes towards sexuality, participants expressed that their sexual rights are still unfulfilled, as they live in a context that perpetuates their dependency. They pointed out low self-esteem, prejudice and social isolation, poor architectural accessibility and scarcity of financial support as some of the barriers to their lives and their sexual health. Finally, participants identified the main needs regarding their sexual health, such as: access to specialized information; training for health professionals. This study gives voice to people with physical disabilities and sheds light into both individual and contextual factors affecting their sexual health. Of utmost importance, this study draws attention to the need for reinforcing sexuality of people with disabilities in the social agenda and brings implications for future research and practice.
\end{abstract}

Keywords Disability · Focus group · Portugal - Qualitative research $\cdot$ Sexuality $\cdot$ Sexual health $\cdot$ Sexual rights

Raquel Pereira

arlpereira.rp@gmail.com

1 Research Group in Human Sexuality, Center of Psychology, Faculty of Psychology and Educational Sciences, University of Porto, Rua Alfredo Allen, 4200-135 Porto, Portugal

2 Life and Health Sciences Research Institute ICVS/3B's PT Government Associate Laboratory, School of Medicine, University of Minho, Braga/Guimarães, Portugal 


\section{Introduction}

The World Health Organization has considered sexual health as a major dimension of global health, which implies a positive approach to sexuality and the recognition of sexual rights of all people [1-3]. Despite the increasing media attention on the topic, the sexual health of people with disabilities is still very stigmatized and poorly addressed by health and social care professionals $[4,5]$. The belief in the supposed asexuality and/or hypersexuality of people living with disabilities, along with the ideology of heteronormativity, may have contributed to the insufficient support of the sexual expression [5]. Ultimately, these circumstances end up limiting the opportunities for people with disabilities to fulfill their sexual needs [4-6]. Based on a participatory paradigm of research, this study aimed to explore the perspectives of Portuguese people living with physical disabilities regarding issues affecting their sexual health, and to assess their sexual needs [7].

The Biopsychosocial model, proposed by the International Classification of Functioning, Disability and Health (ICF), defines disability as the result of the interaction between individual and contextual dimensions [8]. Individual dimensions refer to body functions and structures (impairment), activities (capacity to perform and limitations), and participation (capacity to engage and restrictions in social domains), thus focusing on the direct effects of the impairment [9]. Contextual dimensions include environmental factors (architectural, social and attitudinal factors) and personal factors (psychological or relational factors), which relate to the social construction of disablism [9]. Thus, disability is either aggravated by the contextual factors (acting as disabling barriers or restrictions to participation) or lessened by them (acting as enabling facilitators of participation) [10-12]. Physical disability is defined as a condition where a person experiences significant deviation or loss in a body function or structure that results in limitations in physical activity [8]. As such, people with physical disabilities may experience partial or total restrictions in daily activities, which constrain a full participation in various domains of life, namely the sexual expression and sexual health $[8,13]$.

In fact, sexual functioning may be compromised for individuals with physical disabilities, as their conditions might result in difficulty achieving and maintaining erection, impaired vaginal lubrication and ejaculation, and reduced sensation, sexual pleasure or orgasm $[14,15]$. Previous research suggests a higher prevalence of sexual dysfunction in women with disabilities (between 65.7 and 72.8\%) than in men with disabilities (between 64.4 and $65.9 \%$ ), although they are very similar $[16,17]$. Nevertheless, the traditional models of sexual response may not be the most appropriate to assess the sexual health of people with disabilities [18]. The sexual response of an individual with disabilities may be more variable and adaptive to his or her needs and circumstances when compared to able-bodied people $[19,20]$. For example, people with disabilities may engage in other sexual activities (not only intercourse), or focus on different erogenous body areas, in order to achieve pleasure [19]. Moreover, the negative impact of these difficulties also affects sexual satisfaction- "an affective response arising from one's subjective evaluation of the positive and negative dimensions associated with one's sexual relationship." [21, 22]. Several studies report a decrease on sexual activity and sexual satisfaction in acquired disability [21, 23-26]. Decreased sexual activity may be related to the physical limitations (actual and perceived), perceived changes in sexual attractiveness, and misconceptions about sexuality after disability [25]. In contrast, Crewe and Krause, in a study with couples, have found that higher levels of sexual and life satisfaction were associated with relationships that have begun after the impairment [27]. 
Other intertwined issues may affect the sexual expression of some people with disabilities: socio-sexual isolation (due to architectural or economic restrictions); family overprotection and lack of space for intimacy; a dominant urge for body perfection; lack of sex education on general and specific needs; internalization of normative models; lack of awareness and empowerment on sexual rights [28-30]. These factors entail not only an external social oppression of the sexual expression of people with disabilities, but also the psycho-emotional effects that may lead to a process of internalized oppression $[5,19$, 31-35]. Accordingly, cultural scripts of normative, able-bodied sexuality can have a negative impact on sexuality as they become internalized and make it difficult to explore one's sexuality [4, 33]. In fact, a metasynthesis from Nguyen and colleagues proposed that, due to negative internal factors (e.g. lack of knowledge, negative attitudes and psychological factors) and external factors (e.g. stigma, gender role, lack of support from family and partners, lack of education, unavailable health services, finance and transportation), people with disabilities still face many barriers to their sexual and reproductive health [36].

Regarding sexuality, the Portuguese society has shifted from a rigid and conservative sexual morality, prevailing during Salazar's fascist dictatorship (1933-1974), towards more democratic and equalitarian norms and policies [37]. Nevertheless, it was not until 2013 that "Sim, nós fodemos" ("Yes, we fuck"), an activist group of people with physical disabilities, began to claim the right of a sexual life for people with functional diversity. Through growing visibility, this group has contributed to deconstructing myths and spreading a political message that the right to have a sexual life is as important as the right to accessibility, employment and other basic rights. Health and social care professionals are increasingly recognizing the sexual health and sexual needs of people with disabilities, as well as their professionals' roles in promoting or inhibiting their sexual expression [38-40]. However, there is an overall lack of knowledge and skills amongst professionals, which is related to the discomfort and inability to manage questions to provide information $[39,41$, 42]. Furthermore, research on sexuality and disability in Portugal is scarce and Disability studies are not a well-established research field in Portugal [13, 20].

In sum, the sexual rights and needs of people with disabilities living in Portugal are still poorly fulfilled [43]. Even now, people with disabilities not only are regarded as asexual, but they are also disempowered by a State that continues to rely mainly on the medical power to determine disability's rights $[43,44]$. Therefore, these circumstances end up severely impairing the development of resources to address the sexuality of people with disabilities and emphasize the need to listen to their own perspectives and opinions on the topic.

\section{Aims and Scope of the Study}

This study is part of a larger mixed-methods research project on the sexuality of Portuguese people living with physical disabilities, that aims to understand the role of psychological factors in influencing the sexual health of these people [45, 46]. Striving for deeper and wider understanding of the study's phenomenon, the mixed-methods design of this project is based on a participatory paradigm of research, which improves the researchers' responsibility towards the advocacy issues of their study's participants [7]. According to a participatory paradigm of research, power for the planning and development of the research is shared between the researcher and the participants, which led to the decision to start with a more qualitative approach. In this sense, this is the first study of the project and it aims to explore the perceptions, beliefs, opinions, and attitudes shared by Portuguese people living 
with physical disabilities regarding the issues affecting their sexual health. Thus, the study aims to assess their sexual needs and suggestions, namely for future research and practice.

\section{Methods}

This was a qualitative study, using focus groups to assess the participants' perspectives regarding their sexual health. A qualitative approach helps the researcher in exploring the idiosyncratic and contextual meanings underlying the research questions [47]. As mentioned above, this goes in line with a participatory paradigm of research, since this approach values personal involvement from both participants and researchers and allows for flexibility in data collection and data analysis [7, 47]. Moreover, a Focus Group method is suitable to study the perceptions, beliefs, opinions, and attitudes shared by a certain group regarding a relevant topic [47]. These interviews capture the interaction between the members of the group, and, therefore, they also translate the social reality around the topic [48].

\section{Participants and Setting}

For the current study, participants were recruited from a professional rehabilitation facility in a city in the North of Portugal. The researchers contacted the unit managers and provided written information describing the study and the inclusion criteria, which were as follows: having a physical impairment (e.g. spinal cord injury, multiple sclerosis, amputation, acquired brain injury, etc.); being between 18 and 50 years of age. ${ }^{1}$ In this study, the decision of including people with different physical impairments relates to our interest to account for the psychosocial dimensions of disability, namely the stigma regarding their sexuality, rather than a specific clinical diagnosis. Nonetheless, participants with moderate to severe cognitive impairments were excluded, since they are often incapable of providing informed consent. Also, participants older than 50 years were excluded as age is often a variable that has a negative impact over sexual functioning [49].

During weekly activities, eligible participants were informed about the study and decided whether to participate or not. Two participants declined and withdrew in the beginning of the focus group sessions, due to the sensitive nature of the topic and the need to record the session. A total number of 26 participants (17 men and nine women) volunteered to participate in the study (see Table 1). Participants were divided into four focus groups, with five to nine participants in each group $(9+7+5+5)$. More than half of the participants were single (53.8\%), and most of them had completed at least 9 years of education (73.1\%). Since this was a convenience sample, two groups were more homogeneous regarding their health condition (participants having experienced either traumatic brain injury or stroke) and the other two were more heterogeneous (participants having spinal cord injuries, multiple sclerosis, and amputations, among others). Nonetheless, all the participants had acquired physical disabilities (due to disease or an accident) [50].

\footnotetext{
${ }^{1}$ One of the participants was 51 years old. However, we decided to include him in the focus group session since he manifested a strong will to participate and we considered that his age was not significantly different from the maximum range.
} 
Table 1 Characteristics of focus groups participants $(\mathrm{N}=26)$

\begin{tabular}{|c|c|c|c|c|}
\hline & \multicolumn{2}{|c|}{ Women $(n=9)$} & \multicolumn{2}{|c|}{$\operatorname{Men}(n=17)$} \\
\hline \multicolumn{5}{|l|}{ Age } \\
\hline M & \multicolumn{2}{|c|}{33.6} & \multicolumn{2}{|c|}{37.1} \\
\hline \multirow[t]{2}{*}{ Range } & \multicolumn{2}{|c|}{$22-42$} & \multicolumn{2}{|c|}{$23-51$} \\
\hline & $N$ & $\%$ & $N$ & $\%$ \\
\hline \multicolumn{5}{|l|}{ Marital status } \\
\hline Married/CL & 2 & 22.2 & 7 & 41.2 \\
\hline Single & 5 & 55.6 & 9 & 54.9 \\
\hline Divorced & 2 & 22.2 & 2 & 11.7 \\
\hline \multicolumn{5}{|l|}{ Educational level } \\
\hline $0-4$ years & - & - & 1 & 5.9 \\
\hline $5-6$ years & - & - & 6 & 35.3 \\
\hline $7-9$ years & 4 & 44.4 & 4 & 23.5 \\
\hline $10-12$ years & 2 & 22.2 & 4 & 23.5 \\
\hline $13-15$ years & 3 & 33.3 & 2 & 11.7 \\
\hline \multicolumn{5}{|l|}{ Type of impairment } \\
\hline Spinal cord injury & 1 & 11.1 & 2 & 11.8 \\
\hline Multiple sclerosis & - & - & 3 & 17.6 \\
\hline Amputation & 1 & 11.1 & 1 & 5.8 \\
\hline Traumatic brain injury & 1 & 11.1 & 7 & 41.8 \\
\hline Stroke & 3 & 33.3 & 2 & 11.8 \\
\hline Cancer & 1 & 11.1 & 1 & 5.8 \\
\hline Other* & 2 & 22.2 & 1 & 5.8 \\
\hline
\end{tabular}

CL, common law

*Includes polytrauma and unspecified diagnosis

\section{Ethical Considerations}

This study was performed according to the 1964 Helsinki declaration, and obtained previous approval from the University Ethics Committee and from the Portuguese National Commission for Data Protection. The sessions were carried out only after having a signed informed consent form from all the participants. The first author assured that participants fully understood the aspects of confidentiality.

\section{Data Collection}

Four focus group sessions were conducted between October 2016 and July 2017. Three rooms at the rehabilitation facility were provided for the sessions, due to participants' convenience. The sessions were recorded using a digital voice-recorder and lasted between 58 and $63 \mathrm{~min}$.

The first author began the sessions by appreciating the participation of the volunteers and clarifying the rules of a focus group [47, 48]. Then, participants were encouraged to express their opinions on the current issues of sexual health and their sexual needs, and discussions were introduced by the question: "Accounting from your experience, what are 
the main barriers to the sexual lives of people with physical disabilities?". The researcher allowed the discussion to occur, summarizing participants' opinions and asking for clarification when necessary. Linking questions were used to guide the discussion to more specific topics, for example: "What do you think that society (e.g. health professionals, politics, institutions) should do in order to promote the sexual rights of people with physical disabilities?"; "How may science help to improve the sexual health of people with physical disabilities?". Then, the researcher prompted the key question in order to address the main objective of the study, as follows: "In your opinion, what should a study focused on the sexual health of people with physical disabilities cover?". After asking for final suggestions or questions regarding the discussion, the researcher closed the sessions and finished the recording.

\section{Data Analysis}

The interviews were transcribed verbatim in the Portuguese language and read repeatedly. Some parts of the interviews that were relevant to this article were translated into English. The transcripts were analyzed with the assistance of QSR International's NVivo 11 Software. A conventional content analysis was adopted to analyze the first two transcripts. This is an inductive approach, which is appropriate to describe a phenomenon in study, helping the researchers to gain a deeper understanding of the data and allowing new insights to emerge [51]. Following an iterative process, the transcripts were assessed several times in order to explore the main ideas. Also, the authors have built a research diary to assist with data interpretation. Then, the researchers were able to identify meaning units and to condense them into summarized codes. Codes were sorted into categories and sub-categories, and the meaning of each category was explained and clarified [51]. The focus of the analysis was on the experiences and meanings participants attached to their sexual health and their sexual needs. In a second phase, in order to achieve data saturation, the last two transcripts were assessed, and all the data was revisited and analyzed deductively, focusing on the same perspective. The final abstractions of the meaning units, categories and sub-categories will be displayed by verbatim quotes and explained by the authors' interpretation.

\section{Findings}

Participants' perceptions developed into three main categories: (1) meanings and beliefs about sexuality; (2) experiences of sexuality; (3) necessary changes (see Table 2). Next, we provide a detailed description of these categories and provide excerpts from the sessions. ${ }^{2}$

\section{Meanings and Beliefs About Sexuality}

This category comprises participants' views, opinions and attitudes regarding sexuality and expresses their core beliefs about this dimension of their lives. This category includes two subcategories: (a) Sexuality as a right for independent life; (b) Sexual scripts-from the individual to the couple.

${ }^{2} \mathrm{M}=$ male; $\mathrm{F}=$ female; $\mathrm{FG}=$ focus group. 


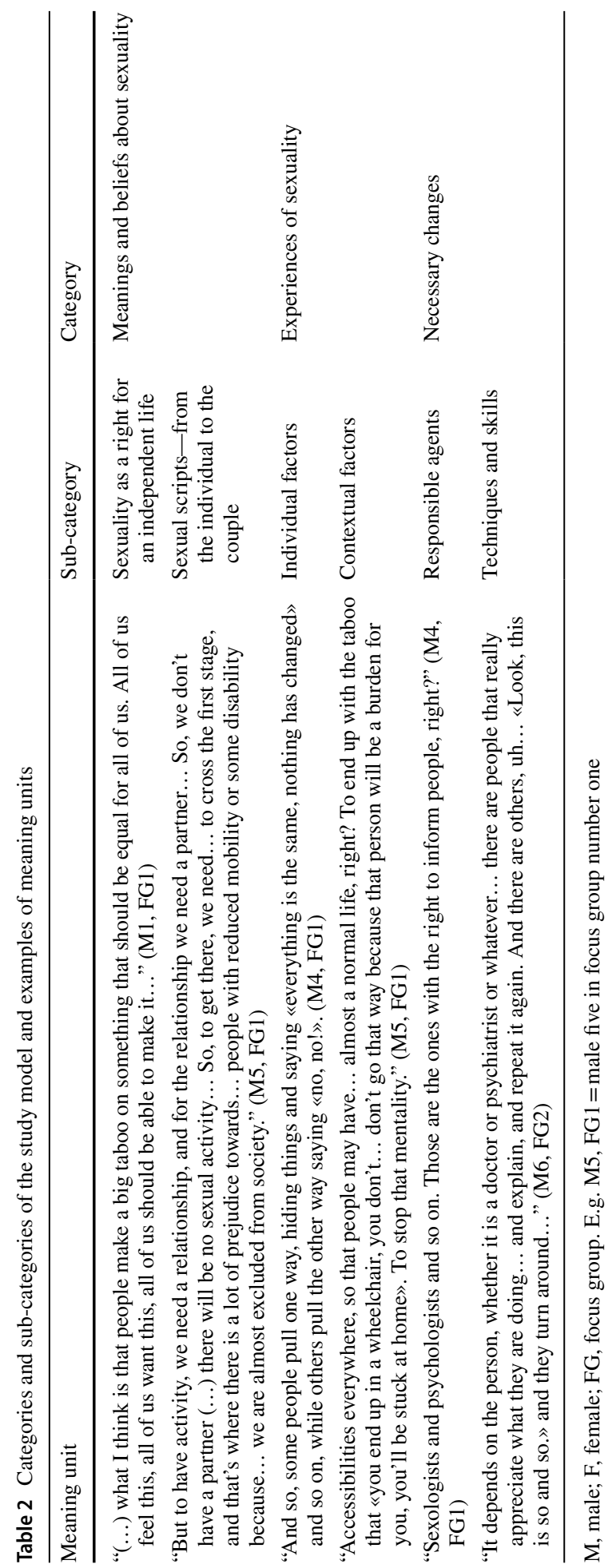


Sexuality as a Right for Independent Life All the participants regarded sexuality and sexual health as fundamental rights within human rights. The discussion led participants to reflect upon the changing perspectives in Portugal, and some participants acknowledged that there has been a recent positive change. Nevertheless, overall, they pointed out the lack of attention and recognition on sexuality issues by health and social care professionals, which leaves people with disabilities with scarce resources to fulfill their needs. Thus, participants expressed their right to have sexuality properly addressed, and called upon the decrease of the stigma around this topic:

"There is now a big change because I remember... three years ago uh... this was really a taboo." (F2, FG1). "No, no, he doesn't know. The thing is (...) he was not informed, he doesn't know and he just stands there." (M4, FG1). "But that part should be covered (...) Everything has to be addressed, right?” (F1, FG3).

Accounting from a holistic perspective of the human being, three groups also discussed the right to an independent living. In their opinion, implementing a social structure for independent living, based on the help of a professional care-giver, would let them carry out their daily activities and pursue their life goals in a more autonomous and dignified way. Ultimately, such structure would bring them more privacy and access to resources to fulfill their sexual needs:

"Taking a shower. With your parents... you have to adjust to their schedule. When there is a person... a third person, you can take a shower whenever you want, you just ask the person." (F4, FG1). "The proposal... the proposal is because... presumably there will be European funds, to train people to be able to... to conduct this kind of work, this would bring more jobs to people, eh... the person acquires dignity." (M5, FG1)

Sexual Scripts-from the Individual to the Couple Participants' experiences expressed their views of sexuality, which translated to diverse definitions depending on the value they attributed to sexuality, affection and intimacy. Participants' views and opinions expressed the diversity of beliefs about sexual activity, sexual preferences and gender roles, although they mostly confined to monogamous and heteronormative standards:

"When two people get together, you see, and they love each other... sex is a consequence" (M5, FG1). "For me... it helps a lot... sex clips" (M1, FG4). "I may feel it in the body, think about models (...) But to imagine... «Oh, if I were with that... with that guy» ... er... I like real things." (F1, FG4). "It helps me to execute (...) the man's function, normal... and er... and to give, it's not supposed that the man has pleasure and the woman doesn't... to give pleasure to the woman..." (M1, FG3).

Some participants discussed the importance of exploring their own body individually, regardless of having a partner. These participants pointed out the disadvantages of restricting sexual expression to an intimate relationship in comparison to the advantages, such as decreasing body shame, knowing erogenous body parts, and enjoying oneself:

But er... (...) to approach sexuality as you do [M5, FG1] (...) it is a little bit restrictive... because you are starting from a point where you need to find a partner to... feel... good, sexually" (M2, FG1). "The sexual part is a little bit like that, to know 
ourselves very well, and explore..." (M1, FG3). "No, no... it's for us, to feel good with ourselves..." (M1, FG4)

Nonetheless, most participants focused on the couple's sexuality. Having a partner seemed to increase the likelihood for professionals to address the topic of sexuality with the participants, as well as the opportunities to explore and accept their own body. Therefore, they stressed out the importance of having someone they could trust by their side, instead of facing the fear of disclosing to someone new:

“This doesn't happen overnight, a person has to... (...) to test the waters, take it easy..." (M2, FG2). "Exactly... since we don't have a partner..." (M2, FG4) "I did it with my wife's help..." (M2, FG3) "A person has to trust the other... in the beginning, he/she has to talk... openly, so the other person knows we have difficulties... and we need a good relationship because of that..." (M2, FG4)

\section{Experiences of Sexuality}

This category addresses participants' daily experiences and describes how they live their sexuality by mentioning different factors that may hinder or facilitate their sexual health. This category includes two subcategories: (a) individual factors; (b) contextual factors.

Individual Factors Participants discussed unique individual characteristics of their sexual lives that were related to how they perceive and experience their body's structures and functions. Giving the diversity of the groups, participants discussed specific characteristics associated with different health conditions, and to what extent they would change their activities. Most participants shared the negative impact of reduced mobility, fatigue, physical appearance and secondary medical effects:

You take medication... that puts you like that" (M1, FG2). "In the bus, if I am coughing, I have to take the scarf and clean the tube, and people start to stare." (M5, FG2).

"Our mobility..." (F2, FG3). "For me, it is the left leg..." (M2, FG3).

Regarding sexuality, participants addressed how they would adapt to sexual activity. Although some participants identified no changes, most participants discussed specific changes they would make in sexual activity, concerning both sexual behaviors and time spent in the activity. Participants reported very diverse experiences, since their engagement in sexual activity changed according to their altered body functions and how they would perceive them:

"In my case, I have no curiosity." (M5, FG1). "So, in my case, if I were going to... to have sex, I would have to take out the prosthesis... I'd have to put the sleeve aside, I'd have to leave everything aside" (M1, FG2). "One does everything exactly the same... but... at our own pace. We have time." (M3, FG2). "I am a virgin since the accident" (M3, FG3). "No... so, you get tired... You can't do it so well.” (M1, FG4). "I feel it is the same." (M3, FG4).

Participants' challenges in sexuality also varied according to their gender. Two groups pointed out the increased difficulties women face in having their sexual and reproductive issues recognized and addressed by health care professionals. Specifically, these participants shared the lack of knowledge and solutions to intervene in the sexual functioning of 
women with paraplegia, as well as the lack of contraceptive alternatives for women who had a stroke. Beyond the lack of resources for women, participants' opinions also expressed the oppression towards women's sexuality:

"As far as I know, for girls, total paraplegia... lots of them...we can still do something, men still can, in most cases... in most cases there's a solution to have an erection... and all the rest. Now, for women, since they lose sensation..." (M4, FG1). "The gynecologist said... «from now on, you can't take anything» (...) and then he said: «oh, but she also doesn't need it, she has nobody» (...) But I am not dead, I am a woman, right? Like men, women also have desire, right?" (M1, FG3)

Finally, another factor affecting sexuality relates to the internalized impact of the stigma around sexuality. Participants discussed how their personal and social perceptions of disability hinder their social participation, as they frequently hid their situation until a very disabling state or avoided places and people that they know will bring them a bigger challenge. Ultimately, this influences how they perceive themselves sexually, leading to sexual inhibition:
"But if there's a person... from the opposite sex, you have certain feelings for her, you even want... to flirt with her. You freeze, you no longer can do that, you no longer think of that." (M2, FG2). "I think there is a great difficulty eh... which is like you were saying, we may like that person, however since that person realizes we have something that... socially, in society, is not regarded as «normal» (...) it brings obstacles, it brings more taboo eh... to develop a relationship with us..." (M1, FG1)

Contextual Factors Participants identified several external factors that influence both positively and negatively the sexual health of people with disabilities. They emphasized proximal factors that do not necessarily relate to the person's health condition, but to their personality and psychological well-being. Several participants recognized their feelings of anxiety about resuming their sexual lives, and some of them would report a negative effect of these thoughts and feelings on sexuality. Some participants considered that their personality changed after the disease, and overall, they regarded mental and emotional well-being as important mechanisms to overcome the physical and social challenges of living with their health condition. Namely, psychological aspects contributing to their well-being were self-esteem and acceptance:

"It changes, because the person, the person... is different" (F2, FG4). "You're always afraid of letting your partner down" (M2, FG4) "I would play with the situation, I'm a little bit like that, I had fun with that" (F1, FG3) "The thing is... you want... you accept what you are..." (M2, FG1). "And if you're not good with yourself, your selfesteem... I think it's an essential part indeed." (M1, FG2)

Moreover, participants valued the role of close support networks. Having friends and family by their side, namely spouses, played a key role in their recovery. Another source of support identified by the participants were the people they met in the institution. By sharing their experiences with someone else in a similar situation helped to ease the suffering and have a new perspective on their challenges. Most groups also identified the importance of the medical staff (e.g. medical doctors, nurses, social workers) that helped them throughout the most difficult stages of their disease. Providing them with the treatments 
but also being available to give confidence and hope was perceived by the participants as a source of support:

\begin{abstract}
"Because if you don't have a good network of friends... and if family is not by our side... they may not be always there... but maybe in that moment... someone is a little bit down and something clicks..." (M1, FG2). "The most important assistance... came from my wife" (M2, FG3). "This here came to relieve my spirit, instead of staying between four walls..." (M2, FG2). "When I go to the hospital, I visit the people I met there" (M5, FG2)
\end{abstract}

Nevertheless, when it comes to their sexuality, some participants also stressed out the role of social networks as obstacles. A participant in FG3 even shares that, since she got her disease, she was abandoned by her partner. Namely, for participants living with their parents and/or having no sexual and intimate partners, their sexual expression was overall unrecognized. They shared that they struggle not just by having to depend on someone and lose their privacy, but also because their families are not open to discuss sexuality with them and help them fulfill their sexual health needs:

"That mentality... comes from our parents" (F4, FG1). "Nobody ever asked me..." (F2, FG3). "I will explain to you. I had a boyfriend, but now he doesn't care about me anymore... he's a «jerk» ... to say the least... It's sad..." (F2, FG3)

Finally, participants addressed more distal factors that influence their daily experiences and, namely, their sexuality. Beyond the impact of the perceived stigma around sexuality and disability, economical and material resources were also discussed by the participants. These were mostly perceived as barriers to a dignified life, thus impacting on their sexual and intimate life:

"But, but I have many friends there [Italy] and I see that... they have everything. Even regarding accessibility..." (M4, FG1) "Now... five thousand for something that should be rightfully ours?" (M1, FG2). "In Portugal, unfortunately, our government wants to increase the natality rate... But if they don't help, how can it be?" (M1, FG3)

\title{
Necessary Changes
}

Accounting from participants' recognition of their sexuality, this category comprises the suggestions and opinions on the necessary actions to improve their sexual health. This category includes two subcategories: (a) responsible agents; (b) techniques and skills.

Responsible Agents Participants identified several intervenors that could play a part in addressing their sexual health issues. Of most importance, participants stressed out the role of researchers and healthcare professionals, either those working in hospitals and rehabilitation centers, or more specialized in sexology. They discussed professionals' role on sexual rehabilitation, especially during early stages of their health. Their experiences expressed the diversity of approaches, in the sense that practitioners globally would talk about sexuality, but sometimes they would not address the issue:

"To have a sexologist... in the center" (M3, FG3). "I think... that science... cannot make much because... this thing is psychological. It has to do... with our 
mind." (F1, FG4). "But... since I reached... post-acute stage, they asked me... and my colleagues too." (M2, FG1). "Never asked that question... nobody, nobody asked me that question." (M3, FG1). "It depends on the person, either a doctor or psychiatrist or whatever..." (M5, FG2). "I think the monitoring should start from the beginning" (F1, FG3). "A talk... with someone skilled" (F2, FG4).

Moreover, regarding specialized professionals and services, some participants also mentioned the need to create the role of the sexual assistant in Portugal, in order to facilitate sexual activities and sexual pleasure by teaching and performing sexual techniques. Not everyone agreed with the suggestion of sexual assistance, mostly due to the lack of information regarding these professionals and beliefs about sexuality. Nevertheless, some participants seemed open and willing to benefit from this service:

"It has everything, except... the sexual act. (...) So to speak, imagine... someone in a wheelchair, who doesn't move, that person will teach him/her techniques, ways to reach... pleasure and..." (F4, FG1). "In my case, that thing from the Netherlands... where there is that kind of assistance... it wouldn't work. I don't want it for me. I would not want it." (M5, FG1). "Regarding the State and everything, someone wants... and the person is there just to give us pleasure..." (M1, FG4).

Participants also covered the role of the political power in changing perspectives towards disability over time. Most of the participants agreed with the importance of the politicians not only to intervene but also to spread the word about the sexuality of people with disabilities. They discussed the relevance of creating political measures to improve accessibilities, economical resources, and health care. Specifically, participants shared their opinions that the political power should create the structures and facilities, and give professionals the resources to effectively address sexual health issues:

"They have to prioritize the topic" (M3, FG1) "If I'm not wrong the only TV show about sexology is in [Cable TV channel], but I think it should be broadcasted on public television" (M5, FG1). "It involves generations, ways of thinking..." (F3, FG1). "It depends, those clinics... public clinics... if it's private, most people don't have money... to go to private clinics" (F1, FG4).

Beyond stressing out the relevance of these intervenors, participants also discussed the need for their own initiative in speaking about their sexual issues. Participants' experiences also diverged in this way, as some of them would be willing to bring out the topic during their recovery but others did not. Although expressing that their sexual health should be included in the social agenda, they also recognized their own role in improving the services they are provided with:

"The person with a disability... should listen to and show interest in talking to a professional to get some... help" (M1, FG1). "But if I were not so... (...) If I didn't have that curiosity for knowing... If I didn't have... a strong will." (F1, FG3).

Techniques and Skills More than identifying possible intervenors, participants suggested techniques and skills that should be developed or improved to address their sexual needs. Overall, they expressed the need for more information, not only about their health conditions and rehabilitation processes, but also regarding sexuality education in general. Participants agreed that public awareness about their sexual rights should be more efficient, 
in order to open the access to the information and resources to deal with specific sexual needs:

"For example, in this situation, for example, more sessions like this one." (M1, FG2). "Explain what sex is... it's not just... intercourse..." (M1, FG1). "Beginning with early sexual education in schools, for example. So that kids are aware that even the disabled..." (M3, FG1). "In hospitals, provide information to the patients" (M2, FG3). “(...) what kind of ways... someone can use... in sex (...) sex positions, right." (F1, FG4).

Furthermore, participants stressed the need to overcome the gaps in the training of health professionals dealing with people with disabilities and their sexual health. Several participants stressed out the need to incorporate both physical and psychological strategies to effectively address the sexual needs of people with physical disabilities. Participants addressed the limitations regarding theoretical and technical skills, but they emphasized the role of personal characteristics and attitudes of the clinician when approaching a person with disabilities. Namely, they valued the skills of empathy and non-judgment, which influence how they perceive and relate to these patients:

"Because usually they talk to normal people, then talking to someone with a disability... there's always a big difference, right? It's always difficult... to put yourself in the other's shoes." (M3, FG1). "I come here and I talk only to [the first researcher], it's about how you are accepted. The impact, to look at someone coming inside... without a leg or in a wheelchair... or using crutches. The person's look..." (M1, FG2). "I think there is no training. I am not aware of any training... there's none." (F1, FG4).

\section{Discussion}

This study aimed at exploring the perceptions, beliefs, opinions, and attitudes shared by Portuguese people living with physical disabilities about their sexual health. Their experiences clarified the importance that participants attributed to sexuality in their lives, and the interpretation of the findings helped to identify several factors that influenced their sexual health. Moreover, participants were asked to express their own perspectives regarding the necessary changes in order to deal with their sexual needs; which brings several implications for research, and also for practice.

Participants' perspectives reflect the need for recognition of their sexual expression and their sexual needs. Their discourses translate a positive and open view of sexuality that has been growing in Portuguese society in the past decades, as well as the changes regarding disability policies [37, 43, 44]. Nevertheless, the focus groups helped to clarify that the sexuality of people with physical disabilities keeps on being socially unappreciated or even forgotten. In fact, it remains hidden by a social structure that perpetuates an idea of people with disabilities as undesirable and dependent [6]. As well as in other developing countries, some individuals with disabilities may live with families or in residences, where they could face limited and repressive attitudes regarding sexuality, thus being deprived from the contexts and opportunities to fulfill their sexual and intimate relationships [29]. Moreover, participants' views on sexuality, overall, can be seen according to the monogamic and heteronormative values embedded in society [4]. Despite discussing the advantages of 
exploring one's body individually, being in a relationship was perceived by most participants as more facilitative of their sexual expression. Specifically, it seemed to help them to cope with the perceived sexual unattractiveness and to legitimize the need to address sexual health by professionals. These findings seem to contradict previous literature reporting a decrease in sexual activity and satisfaction on people with acquired disabilities [23-27]. However, literature on chronic illness and marital functioning suggested that disability may be impacted by the perceived spousal support [52]. Marital satisfaction may act as contextual variable that mediates disability and sexual satisfaction, with a positive impact in perceived sexual health, above and beyond sexual functioning or disability [52-54].

Participants' discourses inform that their experiences of sexuality could be influenced by several factors. At first, there were individual factors, which refer to internal dimensions that are directly related to the health condition. Of utmost importance were the actual and perceived effects of the altered body functions and structures in sexuality, or the "impairment effects" [9]. Participants' shared the different ways in which these alterations would affect their sexual activity, by changing sexual behaviors and taking more time in sexual activities, thus reinforcing the need to adapt the assessment of sexual functioning in people with physical disabilities [18]. Regarding gender, women seemed to face greater difficulties in achieving their sexual goals than men, which is consistent with other studies concluding that women with disabilities were more often regarded as asexual and unattractive [36, 43, 44]. Nevertheless, participants' views emphasized a common process of internalized oppression regarding their sexuality. This process is characterized by psycho-emotional disablism and affects what people think about themselves, which has a negative impact on sexuality, as it leads to sexual inhibition and isolation [33-35].

Additionally, possible contextual or external factors affecting sexuality that are not directly related to the health condition have been identified. Personality traits, as well as having supportive networks, were the main proximal factors identified by the focus groups' participants in their recovering processes. Having a greater capacity to accept the current circumstances seemed to help them cope with the adaptations regarding sexual activity. This is consistent with the literature on the role of third generation cognitive-behavioral variables (e.g. acceptance and commitment) to improve the biopsychosocial adjustment to health conditions [55]. Also, it is important to mention the emotional support they received by professionals and by people with disabilities that they met in the institution. Since disability models are scarce in daily life and media, getting to know other people in similar situations and sharing stories would help the participants in breaking stereotyped ideas of sexuality and disability, and in giving them confidence and hope to overcome difficulties [29]. Beyond the social stigma, and consistent with the literature, participants addressed more distal factors with a negative impact on their sexuality, namely the insufficient economical and material resources to access health services [36]. As such, participants' discourses highlight the incongruences of the Portuguese context, since most policies are already very progressive but, in reality, people cannot entirely fulfill their rights [43, 44].

\section{Limitations}

There are some limitations that must be taken into account for data interpretation. In this study, there was a small, convenience sample, which was circumscribed to a rehabilitation facility in the North of Portugal. Thus, findings may be very restricted to the Northern context and can hardly be generalized to the rest of the country. Respondent bias, associated with the sensitive nature of the topic, may be present as well, which is reinforced by the 
fact that two participants declined to participate even after the explanation of the anonymity and confidentiality of the data. Moreover, although the groups were very diverse regarding their health conditions, all participants had acquired disabilities. According to the literature, people having congenital disability may develop their sexuality with a sense of sexual-concept that includes the disability, but when the disability is acquired, the person may already have a sexual experience that will hamper the adaptation and integration of the disability into their self-concept [5]. Thus, the inclusion of participants with congenital disability could have helped to broaden the discussion towards more positive aspects of living with a disability.

\section{Implications for Research and Practice}

The findings include the participants' suggestions to better address their sexual health and have implications for future research and practice. Of utmost importance, people with physical disabilities need effective political measures that improve architectural accessibilities and economical resources to access health care. Specifically, participants mentioned their interest for sexual assistance, but the discussions revealed that there may be a lack of information on the topic [4]. Regarding the role of researchers and health professionals, the findings point out the need for access to specialized sexology services and sexual rehabilitation from the beginning of the recovery process. These professionals must be able to provide people with reliable information and knowledge about the impact of the health condition on sexuality, as well as strategies to adapt to different sexual activities. Specifically, participants emphasized the need to improve the couples' communication skills. Furthermore, addressing sexuality in an empathic and non-judgmental way was advocated in the discussions, and it is fundamental to avoid further sexual victimization [40]. Combining both physical and psychological strategies is necessary to effectively help people with disabilities in developing a satisfying and pleasurable sexual life.

Future research should focus in clarifying the role of specific factors in the sexual health of people with physical disabilities, namely psychological factors associated with sexuality and the experience of disability (e.g. sexual beliefs, acceptance). Additionally, understanding the current challenges of the professionals dealing with people with physical disabilities regarding their sexual health is much needed [38-42]. Finally, public awareness on the sexual rights of people with disabilities should be developed, in order to empower them to make informed choices and taking initiatives to promote their own sexual health [40].

\section{Conclusions}

This research focused on the sexuality of people living with physical disabilities in Portugal. By using qualitative studies, namely the focus groups, this study gave voice to people with physical disabilities based on personal accounts and provided a unique insight into the discussions around the topic. Findings shed light into both individual and contextual factors affecting the sexual health of people with disabilities and draw attention to long-lasting prejudice and bias. Factors discussed by the participants may be similar to those found previously in the literature [36]. However, the changes in Portuguese society may have contributed to the delay of the discussions around disability sexuality until very recently, although they seem strongly embedded in monogamic and heteronormative standards $[37,43,44]$. Thereby, this research calls into attention the need for the reinforcement 
of the sexuality of people with disabilities in the social agenda, as well as in research and in health, education and rehabilitation professions, for effective recognition and promotion of sexual health of all people.

Acknowledgements This study was supported by a Grant attributed to the first author by the Portuguese Foundation for Science and Technology (SFRH/BD/112168/2015). The authors would like to thank Centro de Reabilitação Profissional de Gaia (Professional Rehabilitation Centre of Gaia), namely Dr. ${ }^{a}$ Ana Correia Barros, Dr. Ivo Adrião, Dr. ${ }^{a}$ Andreia Mota, Dr. ${ }^{a}$ Sandra Guerreiro and Dr. ${ }^{a}$ Isabel Almeida, for their help in the recruitment procedures. We would also like to thank José Fernandes for proofreading the manuscript. Finally, a special thank you to all the participants and their willingness in sharing their opinions for this research.

Funding This work was funded by the Portuguese Scientific Foundation (CPUP UID/PSI/00050/2013; FEDER/COMPETE2020 POCI-01-0145-FEDER; SFRH/BD/112168/2015).

\section{Compliance with Ethical Standards}

Conflict of interest The authors declare that they have no conflict of interest.

Ethical Approval This study was approved by the Ethics Committee of the Faculty of Psychology and Educational Sciences of University of Porto ( $\left.\operatorname{Ref}^{\mathrm{a}} 3-07 / 2016\right)$ and by the National Commission for Data Protection $\left(n^{\circ}\right.$ 15445/2016, N/ref. ${ }^{\text {a } 30187) . ~}$

\section{References}

1. Lottes, I.: Sexual rights: meanings, controversies, and sexual health promotion. J. Sex Res. 50, 367391 (2013)

2. Tiefer, L.: The emerging global discourse of sexual rights. J. Sex Marital Ther. 28, 439-444 (2002)

3. World Health Organization: Defining sexual health: report of a technical consultation on sexual health. Special Programme of Research, Development and Research Training in Human Reproduction, Geneva (2002)

4. Bahner, J.: Legal rights or simply wishes? The struggle for sexual recognition of people with physical disabilities using personal assistance in Sweden. J. Sex. Disabil. 30, 337-356 (2012)

5. Brodwin, M., Frederick, P.: Sexuality and societal beliefs regarding persons living with disabilities. J. Rehabil. 76, 37-41 (2010)

6. Esmail, S., Darry, K., Walter, A., Knupp, H.: Attitudes and perceptions towards disability and sexuality. Disabil. Rehabil. 32, 1148-1155 (2010)

7. Fontes, F., Martins, B., Hespanha, P.: The emancipation of disability studies in Portugal. J. Disabil. Soc. 29, 849-862 (2014)

8. International Classification of Functioning Disability and Health (ICF): World Health Organization, Geneva (2001)

9. Thomas, C.: How is disability understood? An examination of sociological approaches. J. Disabil. Soc. 19, 569-583 (2004)

10. Kennedy, P.: Introduction, context and overview. In: Kennedy, P. (ed.) Psychological Management of Physical Disabilities: A Practitioner's Guide, pp. 3-13. Routledge, London and New York (2007)

11. Loja, E.: Impacto da incapacitação e do ableísmo nas pessoas incapacitadas em Portugal: Fado, cidadania e o eu corporizado (2012)

12. Shakespeare, T.: Disability Rights and Wrongs. Routledge, London (2006)

13. Cardoso, J.: Sexualidade na doença crónica e na deficiência física. Rev. Port. 20, 385-394 (2004)

14. Cole, T.: Sexuality and physical disabilities. Arch. Sex. Behav. 4, 389-403 (1975)

15. Higgins, G.: Sexual response in spinal cord injured adults: a review of the literature. Arch. Sex. Behav. 8, 173-196 (1979)

16. Amidu, N., Owiredu, W., Woode, E., Addai-Mensah, O., Gyasi-Sarpong, K., Alhassan, A.: Prevalence of male sexual dysfunction among Ghanaian populace: myth or reality? Int. J. Impot. Res. 22, 337-342 (2010) 
17. Owiredu, W., Owusu, A., Amidu, N., Quaye, L., Gyasi-Sarpong, C., Dapare, P., Alidu, H.: Sexual dysfunction and sexual quality of life among the physically challenged in the Kumasi metropolis, Ghana. Health Qual. Life Outcomes 13, 3 (2015)

18. Sellwood, D., Raghavendra, P., Jewell, P.: Sexuality and intimacy for people with congenital physical and communication disabilities: barriers and facilitators: a systematic review. J. Sex. Disabil. 35, 227-244 (2017)

19. DiGiulio, G.: Sexuality and people living with physical or developmental disabilities: a review of key issues. Can. J. Hum. Sex. 12, 53-68 (2003)

20. Garret, A., Martins, F., Teixeira, Z.: A actividade sexual após lesão medular - meios terapêuticos [review article]. Acta Méd. Port. 22, 821-826 (2009)

21. McCabe, M., Taleporos, G.: Sexual esteem, sexual satisfaction, and sexual behavior among people with physical disability. Arch. Sex. Behav. 32, 359-369 (2003)

22. Lawrance, K., Byers, E.: Sexual satisfaction in long-term heterosexual relationships: the interpersonal exchange model of sexual satisfaction. Pers. Relatsh. 2, 267-285 (1995)

23. Taleporos, G., McCabe, M.: The impact of sexual esteem, body esteem and sexual satisfaction on psychological well-being in people with physical disability. J. Sex. Disabil. 20, 177-183 (2002)

24. Taleporos, G., McCabe, M.: Relationships, sexuality and adjustment among people with physical disability. Sex. Relatsh Ther. 18, 25-43 (2003)

25. Sadoughi, W., Leshner, M., Fine, H.: Sexual adjustment in a chronically ill and physically disabled population: a pilot study. Arch. Phys. Méd. Rehabil. 52, 311-317 (1971)

26. Sahay, R., Haynes, E., Rao, M., Pirko, I.: Assessment of sexual satisfaction in relation to potential sexual problems in women with multiple sclerosis: a pilot study. J. Sex. Disabil. 30, 227-236 (2011)

27. Crewe, N., Krause, J.: Marital relationships and spinal cord injury. Arch. Phys. Méd. Rehabil. 69, 435438 (1988)

28. Ahumuza, S., Matovu, J., Ddamulira, J., Muhanguzi, F.: Challenges in accessing sexual and reproductive health services by people with physical disabilities in Kampala, Uganda. J. Reprod. Health. (2014). https://doi.org/10.1186/1742-4755-11-59

29. García, A., Álvarez, C.: Sexuality and functional diversity: an analysis from a gender perspective. Procedia Soc. Behav. Sci. 161, 299-305 (2014)

30. Vaughn, M., Silver, K., Murphy, S., Ashbaugh, R., Hoffman, A.: Women with disabilities discuss sexuality in San Francisco focus groups. J. Sex. Disabil. 33, 19-46 (2014)

31. Cole, S., Cole, T.: Sexuality, disability, and reproductive issues through the lifespan. J. Sex. Disabil. 11, 189-205 (1993)

32. Helmius, G.: Disability, sexuality and sociosexual relationships in women's everyday life. Scand. J. Disabil. Res. 1, 50-63 (1999)

33. Williams, T.: Understanding internalized oppression: a theoretical conceptualization of internalized subordination (2012)

34. Reeve, D.: Psycho-emotional dimensions of disability and the social model. In: Barnes, C., Mercer, G. (eds.) Implementing the Social Model of Disability: Theory and Research, pp. 83-100. The Disability Press, Leeds (2004)

35. Reeve, D.: Towards a psychology of disability: the emotional effects of living in a disabling society. In: Goodley, D., Lawthom, R. (eds.) Disability and Psychology: Critical Introductions and Reflections, pp. 94-107. Palgrave, London (2006)

36. Nguyen, T., Liamputtong, P., Monfries, M.: Reproductive and sexual health of people with physical disabilities: a metasynthesis. J. Sex. Disabil. 34, 3-26 (2015)

37. Alarcão, V., Machado, F., Giami, A.: Traditions and contradictions of sexual function definitions for Portuguese heterosexual men and women: medicalization and socially constructed gender effects. Sex. Relatsh Ther. 1-18 (2015)

38. Rowen, T., Stein, S., Tepper, M.: Sexual health care for people with physical disabilities. J. Sex. Méd. 12, 584-589 (2015)

39. Couldrick, L., Sadlo, G., Cross, V.: Proposing a new sexual health model of practice for disability teams: the recognition model. Int. J. Ther. Rehabil. 17, 290-299 (2010)

40. Linton, K., Rueda, H., Williams, L., Sandoval, A., Bolin, S.: Reproductive and sexual healthcare needs among adults with disabilities as perceived by social workers. J. Sex. Disabil. 34, 145-156 (2015)

41. Tugut, N., Golbasi, Z., Erenel, A., Koc, G., Ucar, T.: A multicenter study of nursing students' perspectives on the sexuality of people with disabilities. J. Sex. Disabil. 34, 433-442 (2016)

42. Kazukauskas, K., Lam, C.: Disability and sexuality: knowledge, attitudes, and level of comfort among certified rehabilitation counselors. Rehabil. Couns. Bull. 54, 15-25 (2009)

43. Pinto, P.: Between the lines: a critical discourse analysis of disability policy in Portugal. Disabil. Stud. Q. 31 (2011) 
44. Pinto, P.: At the crossroads: human rights and the politics of disability and gender in Portugal. Eur. J. Disabil. Res. 5, 116-128 (2011)

45. Venkatesh, V., Brown, S., Bala, H.: Bridging the qualitative-quantitative divide: guidelines for conducting mixed methods research in information systems. MIS Q. 37, 21-54 (2013)

46. Shannon-Baker, P.: Making paradigms meaningful in mixed methods research. J. Mix. Methods Res. 10, 319-334 (2016)

47. Braun, V., Clarke, V.: Interactive data collection 2: focus groups. In: Braun, V., Clarke, V. (eds.) Successful Qualitative Research: A Pratical Guide for Beginners. Sage, London (2013)

48. Freeman, T.: 'Best practice' in focus group research: making sense of different views. J. Adv. Nurs. 56, 491-497 (2006)

49. APA: Diagnostic and Statistical Manual of Mental Disorders-DSM-5. American Psychiatric Publishing, Washington, DC (2013)

50. Bogart, K.: The role of disability self-concept in adaptation to congenital or acquired disability. Rehabil. Psychol. 59, 107-115 (2014)

51. Hsieh, H., Shannon, S.: Three approaches to qualitative content analysis. Qual. Health Res. 15, 12771288 (2005)

52. Leonard, M., Cano, A., Johansen, A.: Chronic pain in a couples context: a review and integration of theoretical models and empirical evidence. J. Pain. 7, 377-390 (2006)

53. Qaderi, K., Merghati Khoei, E.: Sexual problems and quality of life in women with multiple sclerosis. J. Sex. Disabil. 32, 35-43 (2013)

54. Schairer, L., Foley, F., Zemon, V., Tyry, T., Campagnolo, D., Marrie, R., Gromisch, E., Schairer, D.: The impact of sexual dysfunction on health-related quality of life in people with multiple sclerosis. $\mathrm{J}$. Multiple Scler. 20, 610-616 (2013)

55. McCracken, L., Vowles, K.: Acceptance and commitment therapy and mindfulness for chronic pain: model, process, and progress. Am. Psychol. 69, 178-187 (2014) 